\title{
SHIFAYAAB - Centralized Platform for Vaccination Program
}

\author{
Khizar Hayat ${ }^{1}$, Mobeen Nazar ${ }^{1,2}$, Taimoor Khalid ${ }^{1}$, Wissam Amin ${ }^{1}$
}

\begin{abstract}
Vaccinations are very essential for the prevention of harmful diseases. However, the implementation rate of vaccination varies in different parts of the world. Many countries struggle to achieve the maximum immunization ratio due to their vaccination practices and methodologies. However, the authors have developed a solution to strengthen the vaccination procedure. SHIFAYAAB, Proposed Methodology in this paper provides a centralized platform for different healthcare organizations and hospitals, working on various vaccination programs. The idea is to collectively provide a centralized database for the vaccination programs by integrating the platform with the healthcare organizations and hospitals, to enhance and improve the vaccination procedure for the workers as well as the public. SHIFAYAAB proposes automation of the vaccination procedure by replacing the old school vaccine schedule card-reports with autonomous systemgenerated microplans. It will assemble the vaccination records and provide a user-friendly platform for the vaccinators to carry out the vaccination process. It will also provide children parents a platform to keep track of their vaccination progress by monitoring their microplan along with regular notification reminders from the platform.
\end{abstract}

Keywords- Vaccination, Immunization, Centralized Platform, Microplan, Digital Scheduling, Reminders.

\section{INTRODUCTION}

Vaccinations are an important part of public health. Hajj Hussein et al., (2015) stated that Vaccines prevent the spread of dangerous, contagious, and deadly diseases such as measles, polio, mumps, chickenpox, whooping cough, diphtheria, and HPV.

A lot of advancement and progress has been made in the field of health sector over the years. Many new cures, treatments, and vaccines have been developed and discovered around the world. But unfortunately, in the midst of all that Pakistan and Afghanistan are the only two countries still fighting polio.

The vaccination coverage rate is one of the factors that determine the immunization ratio, which is gradually increasing in all parts of the world. However, despite that, there are many other problems linked to the vaccination procedure especially in countries like Pakistan and Afghanistan such as lack of proper health infrastructure, vaccine maintenance, vaccinator facilities, lack of awareness and cultural objections [4][5].Considering all the vaccination-related issues, a smart solution is developed, SHIFAYAAB. A centralized platform for our respective vaccination stakeholders, hospitals/healthcare organizations, vaccinators, and the public. It will help the organizations to manage the vaccination procedure digitally by automating the entire procedure, it'll reduce the workload of vaccinators and make their job much easier as well.

Bahria University Karachi Campus $(B U K C)^{1}$, Malaysian Institute of Information Technology (MIIT) UniKL ${ }^{2}$
It'll let the public get into the procedure loop as well by providing them a dedicated platform for vaccination. This paper cover the

immunization factor as for the vaccination the Section II of literature review shows all the things that were covered for getting the background of this paper.

\section{LITERATURE REVIEW}

This part covers the literature review that has been done in the past for the immunization field and provides all the details of the publication done in the past regarding immunization which includes the title of the paper along with its authors, the year it got published, summary and the research gap that has been discovered. The study depicts that in the past, very limited work was done in the field of immunization. Our application named SHIFYAAB addressed some of those gaps.

Firstly survey has been carried out which shows some of the areas of Interior Sindh Only have immunization rate of $29 \%$. Chart below show the coverage of different Provinces of Pakistan in terms of Vaccination Coverage. The Literature show that there is No Centralized Data, No Proper Scheduling and No Standard Procedure is being followed for Vaccination. For that purpose further literature review has been done that is covered below in this section according to Research Papers.

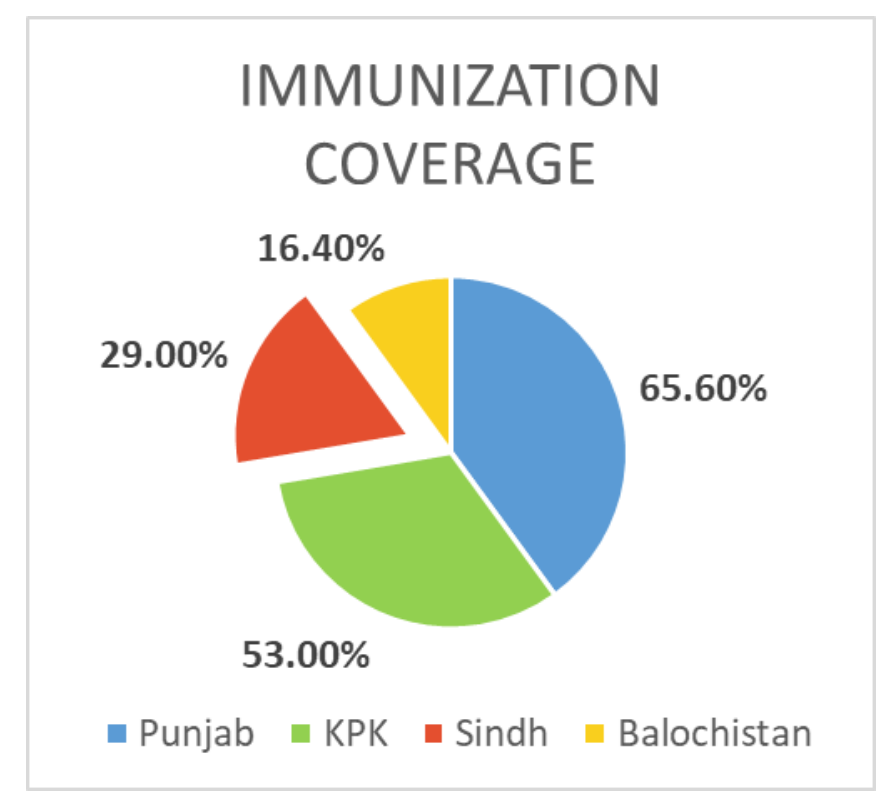

Figure 1: Pakistan Immunization Coverage

In [1] a very useful and helpful Immunization Reminder System has been proposed to provide another option to the public for reminding them about the vaccination dates. This proposed solution will help improve the on-time 
immunization but it will add an extra layer on top of the procedure parents have to deal with their child immunization.

Research in [2] proposed to redesign the old Health Cards being used by the developing countries to carry out vaccination procedures. However, despite redesigning, updating them they are usually underutilized, they are unable to fulfil their desired purpose and become a liability for the people at times.

The proposed solution by the authors in [3] was very helpful in improving the vaccination procedure and increasing the on-time immunization ratio. However, due to lack of unified data and manual records, the solution was hard to execute and not fully effective.

The authors performed a very vital experiment in [8] to conclude that many parents are willing to accept new technology. However, in this modern era of technology, usability is very essential, and targeting the right means of the usability will only work and help the cause.

In [9] authors carried out very important research on the underutilization of Immunization Cards. It is very correctly pointed out by the researchers. However, there are plenty of other important elements of the procedure that are being underutilized. Therefore, as a solution, these important elements should be made part of the procedure instead of utilizing them separately.

The research carried out by the authors in [10] was very valid as people tend to take immunization for granted. Therefore, it becomes the responsibility of everyone to spread awareness regarding the importance of immunization. This process needs to be executed on the mass level since many people don't have the means or facilities like others.

In one of the research in [11], the authors have proposed and developed a very useful and smart solution for the vaccination procedure which will help both the doctors and public to monitor and be a part of the vaccination procedure. Automating the procedure is the key to take the vaccination procedure to the next level. However, the proposed solution doesn't work around centralized data and lacks other important features required for the vaccination procedure.

Shifayaab has proposed and developed a solution considering all the possible loops and drawbacks of the current practices of vaccination procedures being carried out in the different parts of the world especially in developing countries. The researchers have proposed a centralized platform for Vaccination Programs for Hospitals, Vaccinators, and Parents. The proposed solution, SHIFAYYAB is developed after studying all the drawbacks and cons of the current vaccination procedure. The authors have considered different solutions proposed by the researchers over the years and merged them into a single solution in order to improve the vaccination procedure and make it effective.

SHIFAYAAB proposes the Automation of the vaccination procedure by generating vaccine schedules of children autonomously using a unified and centralized database integrated to respective hospitals and healthcare organizations unlike suggested earlier.
It emphasizes the importance of public awareness regarding Immunization just like other researches. But it suggests to speared awareness using correct means and medium. Considering all the factors such as Language, Feasibility, Usability, and Reliability. It proposes to omit the old Immunization health card which usually turns out to be a liability for the parents and is usually underutilized. Instead, a smart card (similar to Debit/Credit cards) is to be introduced which will contain a Unique Profile number that can be used by the children parents to log in to the platform and monitor all the vaccination procedure details of their children without concern of carrying manual Immunization health card with them all the time during vaccination. It also proposes to provide the parents with Reminder SMS and Emails to improve the on-time immunization as suggested by other researchers. But it will not only notify the parents by sending out mere notifications. It'll notify them by using proper standard reminder protocols such as When to remind, what time to remind, in which language to remind etc. It proposes to provide a detailed analysis and reporting of the vaccination procedures to the stakeholders using the unified and centralized database. To improve the Immunization coverage by targeting certain problems and issues.

\section{Methodology}

The governments and authorized organizations have been implementing different solutions to improve the vaccination procedure over the years in different parts of the world. Researchers proposed and developed dedicated mobile applications for parents, redesigning immunization health cards, computer reminders but the problems and issues remain and are yet to be eradicated.

Therefore, a unified platform comprising all the possible required solutions such as record keeping, digital scheduling, procedure automation, public awareness, computer-based notifications will improve the vaccination procedure and make it simpler for all the respective stakeholders[6][7].

The Proposed Methodology of SHIFAYAAB is described in Figure 1. SHIFAYAAB is accessed by visiting its website and navigating to the portal using the desired module. In terms of the new beginning, the Admin Module will be accessed first. Admin will register a Hospital/Healthcare organization and assign Vaccinators to it after registering them as well. When a user/child visits for vaccination, he/she will be registered to the system and provided a Card by the vaccinator. This card will be labelled with a unique identification number that will be used by the child parents to proceed or check his microplan progress. Upon user/Child registration, the system will autonomously generate the microplan of the user/child. (I.e. What doses are to be given and when). The vaccinator will proceed with the vaccination and update the user/child record accordingly. Database will contain all the data of the children and hospitals that are registered on Shifayaab. The child parent will be notified of every activity on his cell phone via computer-based Calls and SMS. Meanwhile, child parents can check and monitor his/her microplan progress. They'll receive reminder notifications before their next visit as well according to their respective microplan. 


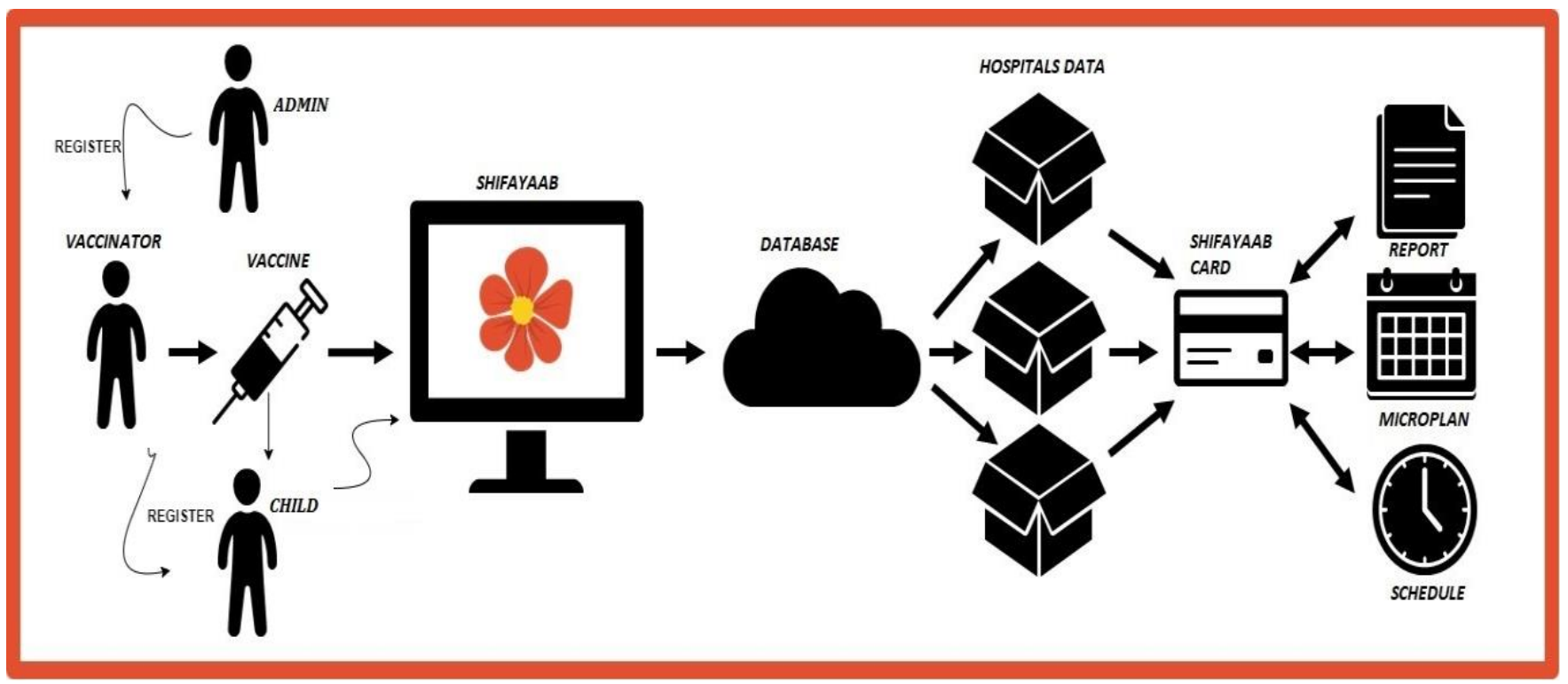

Figure 2: Proposed Methodology

In Figure 3. The Website breakdown structure is provided with all the necessary modules that will be implemented in the website development. There are three modules that will be developed in the proposed methodology which includes:

Admin Module - Responsible for all the major activities like adding hospital and managing things.

Vaccinator Module - Responsible for adding patients and updating their micro-plan accordingly.

User/Child/Patient Module - User Module is there for the children parents, to monitor their child vaccination progress.

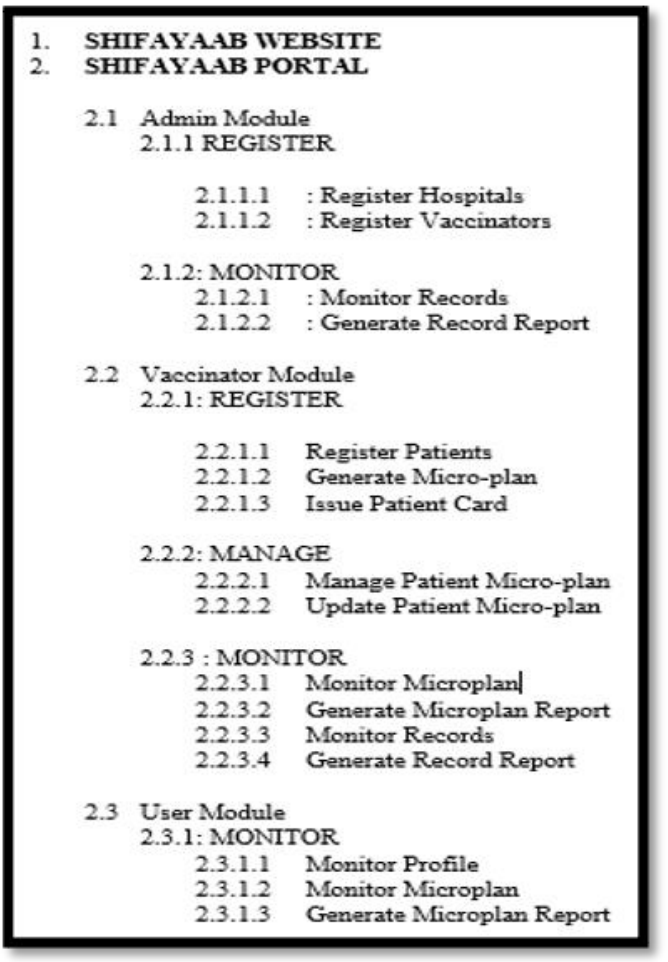

Figure 3 : Work Breakdown Structure

\section{SHIFAYAAB}

This section describe the tools and techniques needed to develop the centralized system of Shifayaab along with the features that were presented in the system its design overview according to the requirement metrics and working.

\section{A) TOOLS \& TECHNIQUES}

SHIFAYAAB comprises of following tools and software:

\section{I) Web Browser}

Browser is compulsory to access the portal from anywhere. It is compatible to all the web-browser e.g. Google Chrome, Firefox and Opera.

\section{II) Front-End}

Front-End is developed using following technologies:

- HTML

- CSS

- JavaScript

- Bootstrap

III) Back-End:

Back-End is developed using following technologies:

- Python

- Flask

IV) Database:

MySQL for the Database and tool for it is MySQL Workbench.

\section{B) FEATURES}

Following are the main features and objectives of SHIFAYAAB:

\section{I) Microplan}

System autonomously generates vaccination schedule of the respective vaccination programs for the patients. This includes the necessary requirements such as Date, Dose, etc.

\section{a) Scheduling}

It provides the whole schedule of dates that are to be followed for the development of microplan. It digitalizes the old Immunization Health Card procedure.

\section{b) Notification}


It generates computer based notifications to remind and update the children parents about their microplan on the scheduled date and prior to it as well.

\section{c) Awareness}

It will help in spreading public awareness regarding the importance of vaccination through its user/child/patient module which is to be used by the public. It is also supports multilingual display for the better and clear understanding of public.

\section{II) Database}

The database requirement of SHIFAYAAB is very simple and essential, as it is one of the core requirements of the whole project. Our database maintains and represents the relationship of the table corresponding to our stakeholder functionality. The database includes the following tables:

- Admin

- Vaccinator

- User

Apart from the tables, the database of SHIFAYAAB is utilize for some other database functionalities, which are major of the project that includes:
- Patient Registration

- Hospital Registration and Record

- Microplan Generation

- Vaccine Scheduling

- Notification

- Vaccination Record

\section{III) Reporting}

System will provide analytical reports of the vaccination programs and microplan progress.

\section{C) Design Overview}

Function oriented methodology is used in the project because it is comprised of small subsystems like data entry, reporting, Microplan generation, admin monitoring, notification generation, and Vaccinator and hospital record maintenance. Table 1 below show the major components of the Project along with the major requirements covered.

The architecture of SHIFAYAAB is Client-Server Architecture described in figure 4. Below, where the server hosts, delivers and manages all the resources and services.

Table 1: Requirement Metrics

\begin{tabular}{|c|c|c|c|c|c|}
\hline & & \multicolumn{4}{|c|}{ Components } \\
\hline & & \multirow[t]{2}{*}{ Website } & \multicolumn{3}{|c|}{ Portal } \\
\hline & & & $\begin{array}{l}\text { Admin } \\
\text { Module }\end{array}$ & $\begin{array}{l}\text { Vaccinator } \\
\text { Module }\end{array}$ & $\begin{array}{c}\text { User/Child } \\
\text { Module }\end{array}$ \\
\hline \multirow{7}{*}{ 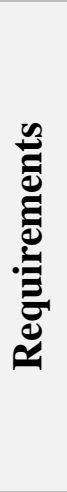 } & Record & & $\mathbf{x}$ & $\mathbf{x}$ & \\
\hline & Monitoring & & $\mathbf{x}$ & $\mathbf{x}$ & $\mathbf{X}$ \\
\hline & $\begin{array}{l}\text { Awareness } \\
\text { and Guide }\end{array}$ & $\mathbf{X}$ & & & $\mathbf{x}$ \\
\hline & $\begin{array}{c}\text { Vaccine } \\
\text { Scheduling }\end{array}$ & $\mathbf{x}$ & $\mathbf{x}$ & $\mathbf{x}$ & \\
\hline & Notification & & & & $\mathbf{x}$ \\
\hline & $\begin{array}{l}\text { Microplan } \\
\text { Generation }\end{array}$ & & & $\mathbf{x}$ & \\
\hline & Reports & & $\mathbf{x}$ & $\mathbf{X}$ & $\mathbf{X}$ \\
\hline
\end{tabular}
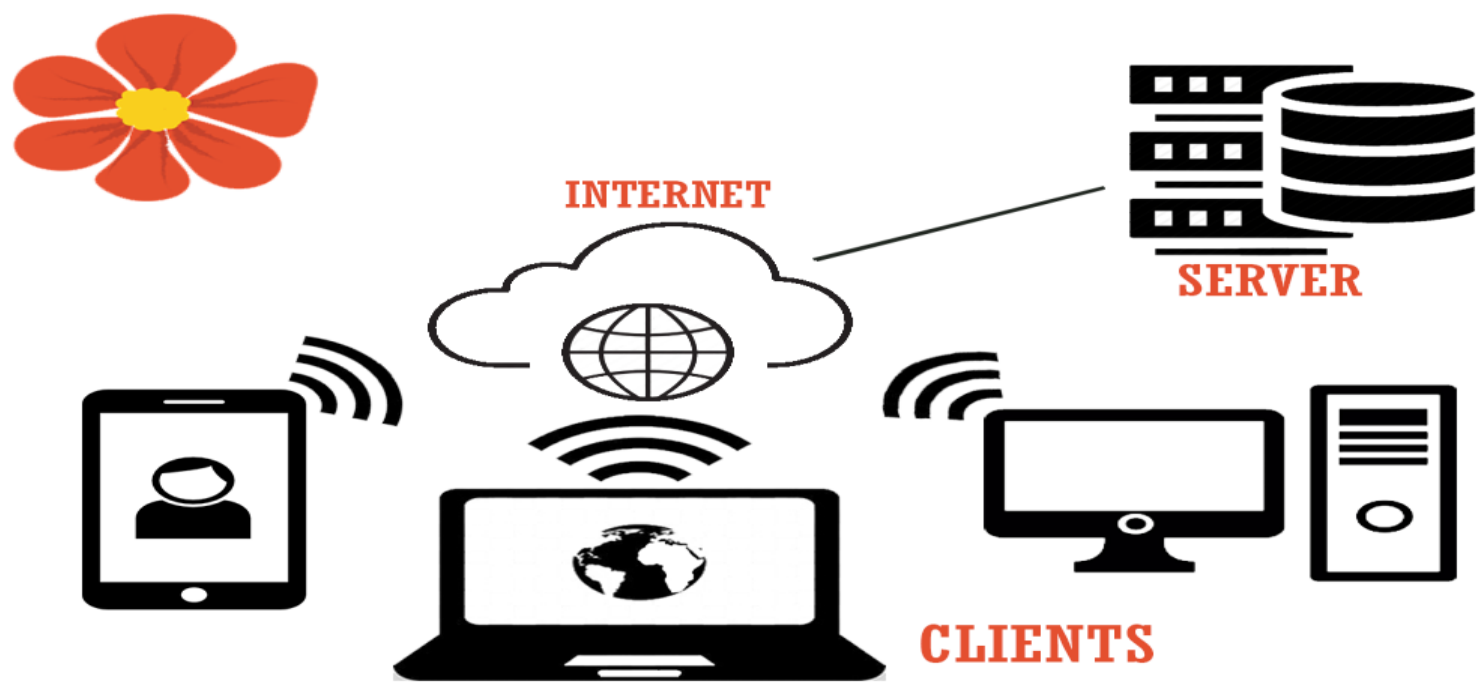

Figure 4: Architecture Diagram 


\section{D) Working}

This section describes the working of Shifayaab and about its modules. It will consist of the following three modules:

Admin Module is to be used by the Administrators only. It can register, modify and monitor entire data. However, the most important privilege is that it can register Hospitals / Healthcare organizations and Vaccinators.

The Second module will be the Vaccinator Module is to be used by Vaccinators only, the vaccinators are already assigned to certain Hospitals / Healthcare organizations by the Administrators. However, they can register users/children and process their microplan accordingly.
The last module will be the users/children Module is to be used by the child parents only. Child parents can only monitor the progress of their microplan. However, they can learn and educate from the tutorials and content available on the User/Child Module as well.

\section{RESULTS}

Table 2. Below show the interfaces of the implementation of the Shifayaab website it includes three columns in which the first column Title represents the name of the interface, the second column gives the description of the interface and the third column shows the picture of the interfaces of different webpages.

Table 2: Interfaces of SHIFAYAAB

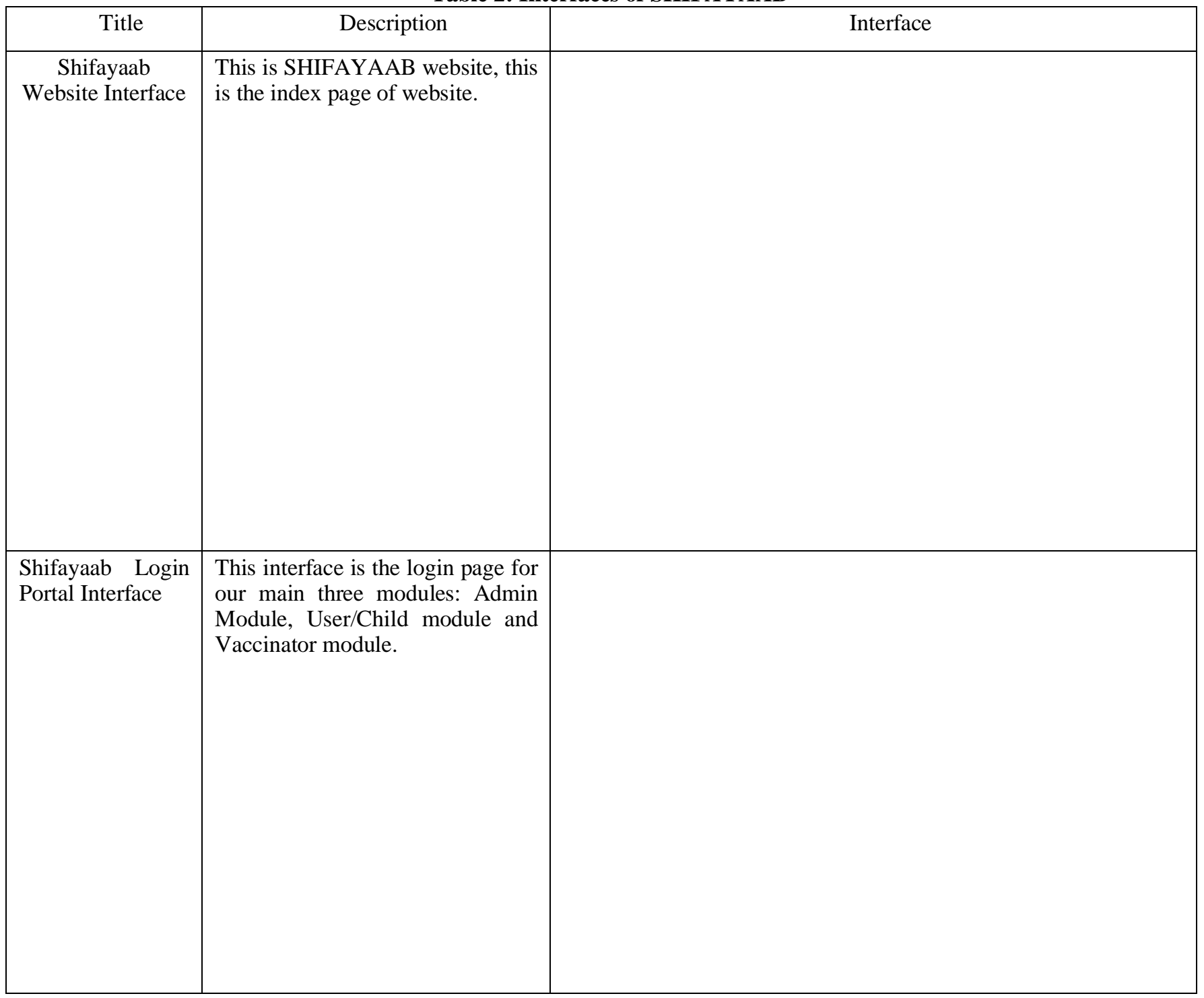




\begin{tabular}{|c|c|c|}
\hline $\begin{array}{l}\text { Shifayaab Admin } \\
\text { Dashboard } \\
\text { Interface }\end{array}$ & $\begin{array}{l}\text { This is main Admin dashboard } \\
\text { where the admin can register } \\
\text { hospitals and vaccinator. } \\
\text { Moreover, monitor all the other } \\
\text { details and record of patients. }\end{array}$ & 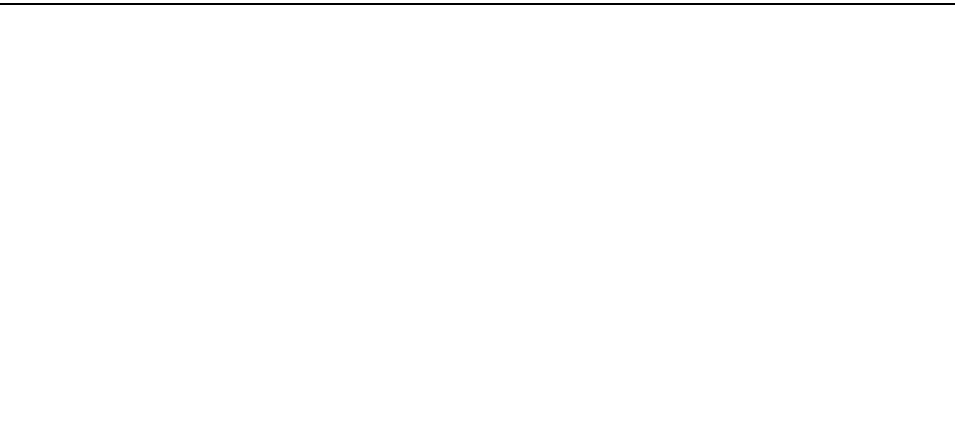 \\
\hline $\begin{array}{l}\text { Shifayaab } \\
\text { User/Child } \\
\text { Dashboard } \\
\text { Interface }\end{array}$ & $\begin{array}{l}\text { This interface is Child Info } \\
\text { dashboard, in which Child Parents } \\
\text { can monitor their microplan by } \\
\text { visiting their profile. }\end{array}$ & \\
\hline $\begin{array}{l}\text { Shifayaab Child } \\
\text { Profile Interface }\end{array}$ & $\begin{array}{l}\text { This interface displays Child } \\
\text { information and some important } \\
\text { guidelines in multiple languages } \\
\text { for the ease and understanding of } \\
\text { Child Parents. }\end{array}$ & \\
\hline $\begin{array}{l}\text { Shifayaab Child } \\
\text { Microplan Details } \\
\text { Interface }\end{array}$ & $\begin{array}{l}\text { This interface displays the } \\
\text { Microplan details of the child } \\
\text { named "Sarah" who is registered } \\
\text { for polio vaccination, it shows the } \\
\text { program status of the child. }\end{array}$ & \\
\hline
\end{tabular}




\begin{tabular}{|c|c|c|}
\hline $\begin{array}{l}\text { Shifayaab Help } \\
\text { Interface }\end{array}$ & $\begin{array}{l}\text { This is the helpdesk of our portal; } \\
\text { it contains important FAQs to help } \\
\text { out the Child Parents. }\end{array}$ & \\
\hline $\begin{array}{ll}\text { Shifayaab } & \text { Help } \\
\text { Feedback } & \\
\text { Interface } & \end{array}$ & $\begin{array}{l}\text { This interface displays the second } \\
\text { part of helpdesk; it is for } \\
\text { collecting feedback form the Child } \\
\text { Parents. }\end{array}$ & \\
\hline $\begin{array}{l}\text { Shifayaab } \\
\text { Vaccinator } \\
\text { Dashboard } \\
\text { Interface }\end{array}$ & $\begin{array}{l}\text { This is Vaccinator dashboard } \\
\text { interface, where vaccinators can } \\
\text { register Childrens and monitor } \\
\text { record of their microplans. }\end{array}$ & \\
\hline
\end{tabular}




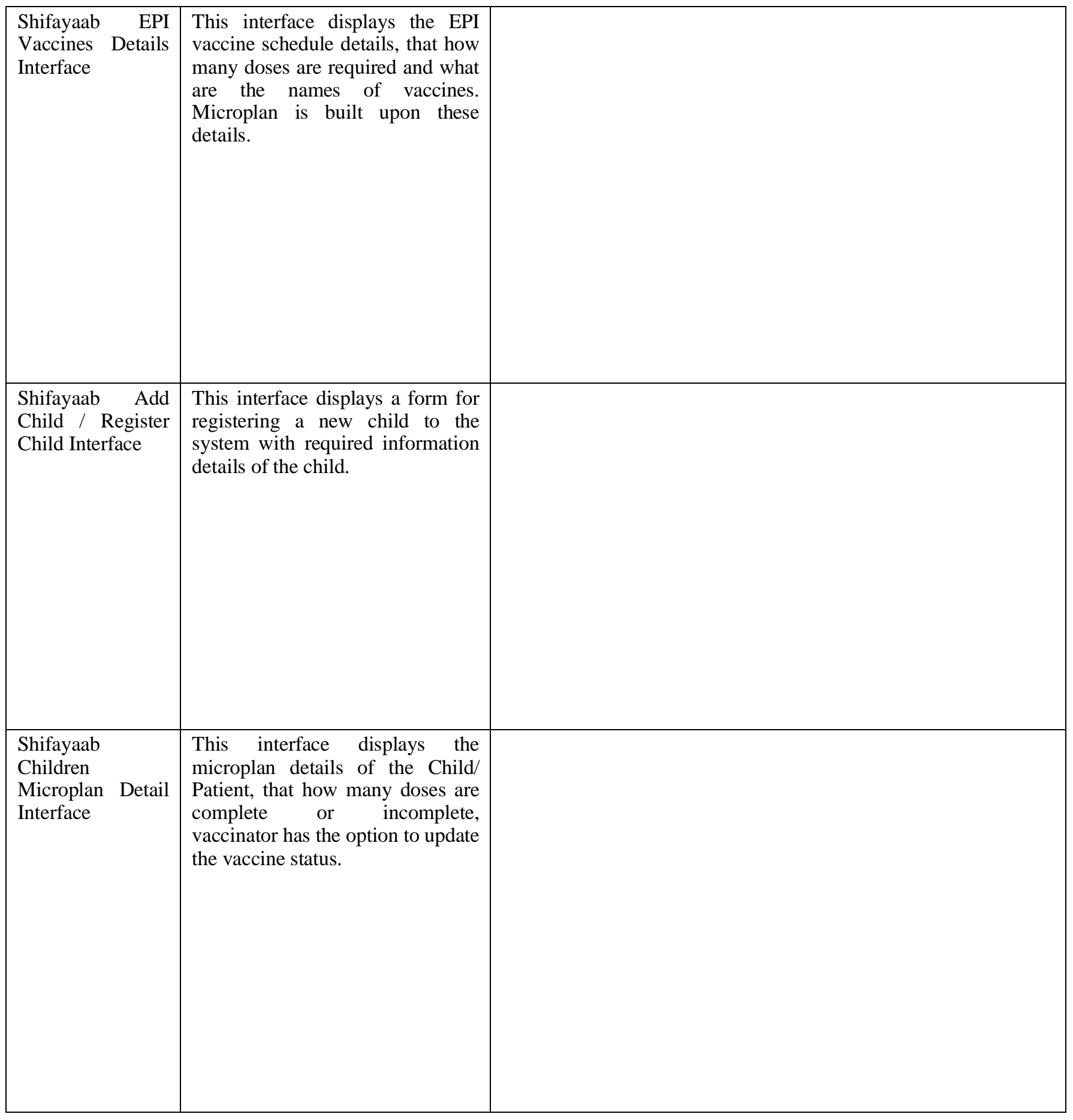




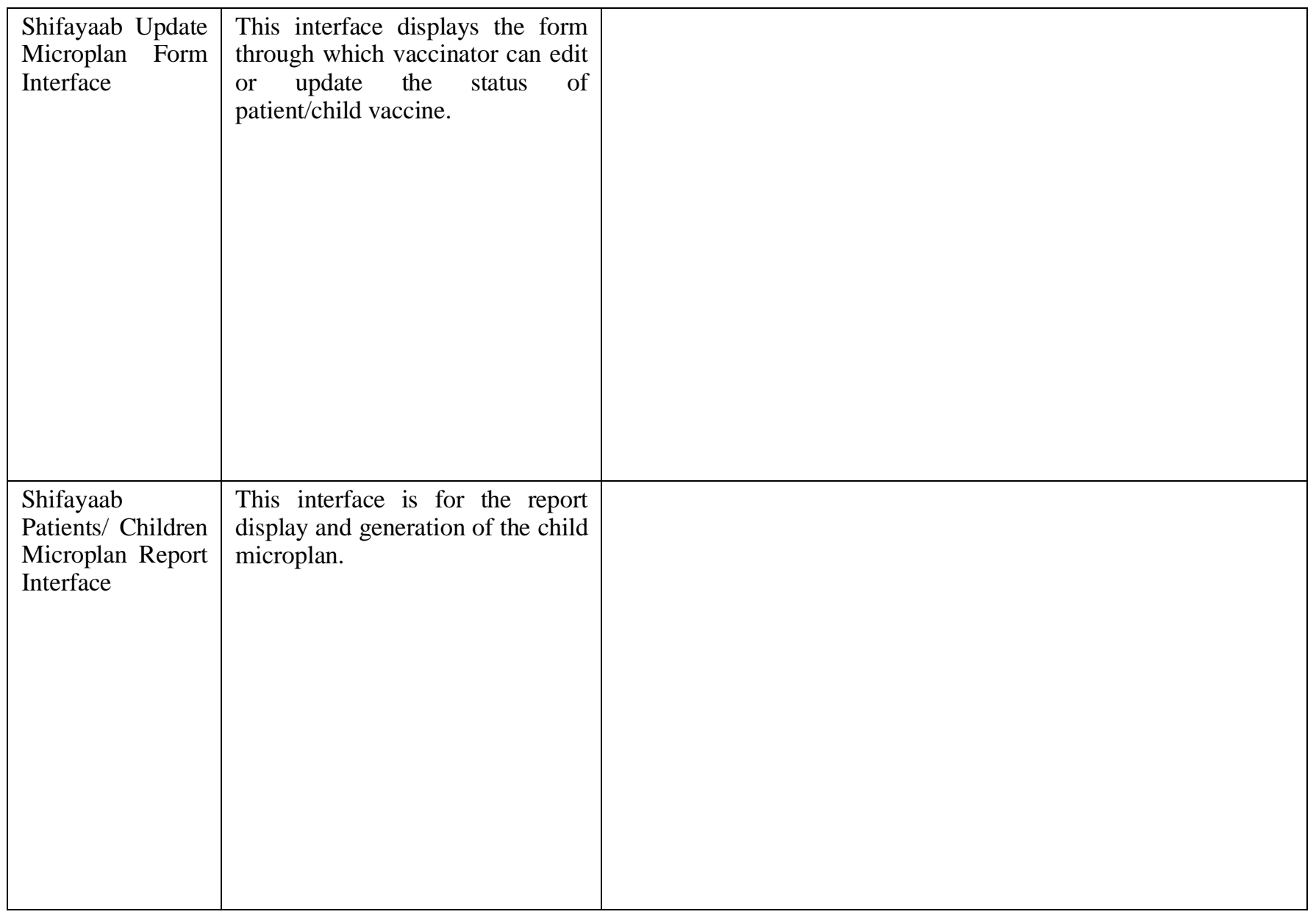




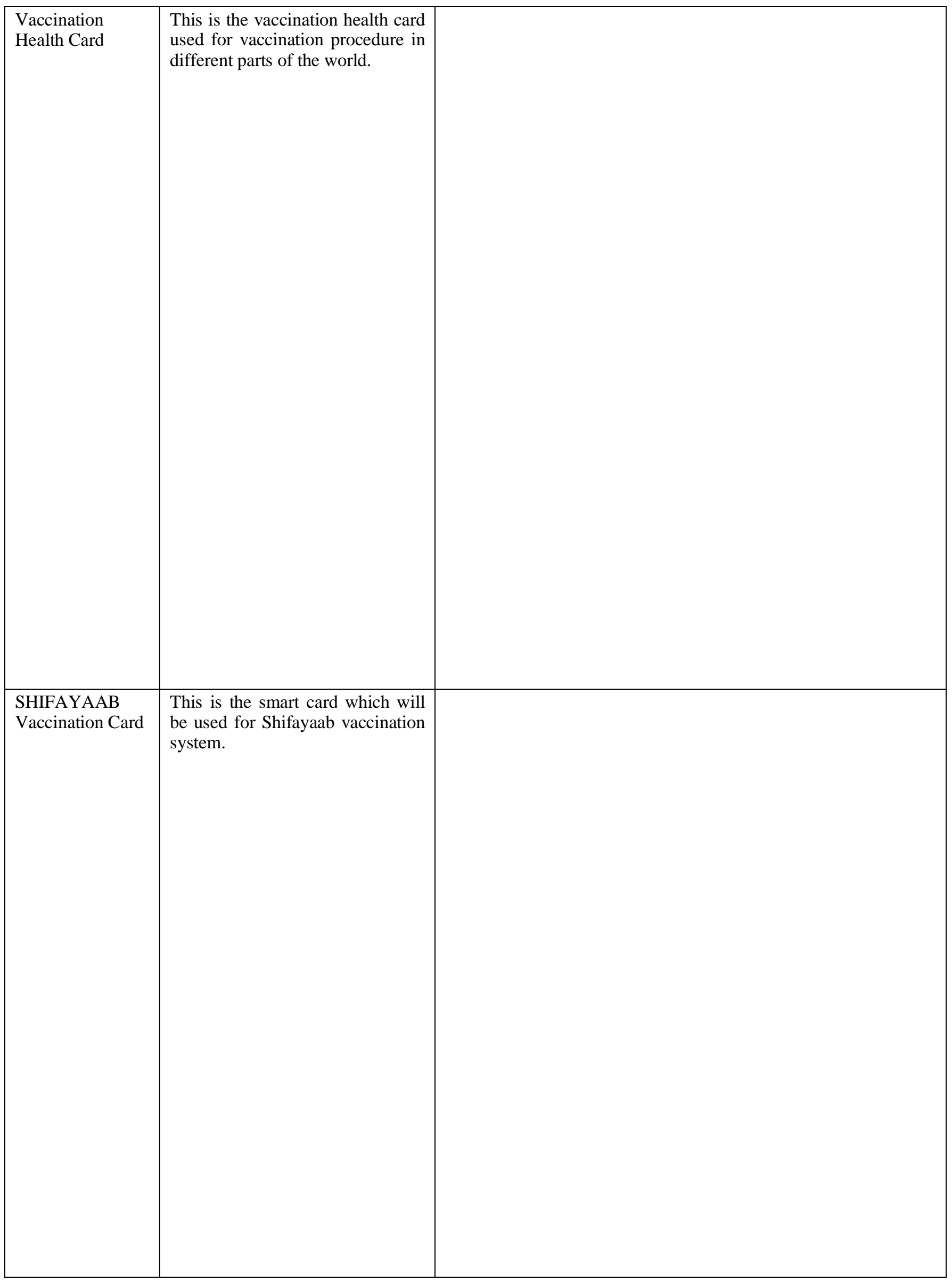




\section{CONCLUSION}

In this current modern era of science and technology, despite human progress there are some essentials need for human body that are needed in any circumstance otherwise its consequences are turn out bad. Similarly, SHIFAYAAB is there to support the vaccination programs. In developed countries, these systems are automated to some extent, it is not a problem for them but in countries like Pakistan and other developing countries, we don't have any centralize system that can monitor and manage the whole vaccination procedure.

It can be concluded that SHIFAYAAB will not only improve the vaccination procedure but open new doors of exploration for healthcare by enabling the organizations to manage the entire procedure digitally, automation will strengthen the vaccination infrastructure, increase the

Immunization ratio and provide standard valuable reporting. Future work is to enhance the platform and make it smart by integrating AI into the system and establish ways to spread awareness of vaccination along with providing a mobile application platform for this.

\section{REFERENCES}

[1] Peck, J. L., Stanton, M., \& Reynolds, G. E. (2014). Smartphone preventive health care: parental use of an immunization reminder system. Journal of Pediatric Health Care, 28(1), 35-42.

[2] Batool, A., Ali, U., Razaq, S., \& Naseem, M. (2016, June). Child Immunization Health Card Redesign: an Iterative, User-Centered Approach. In Proceedings of the Eighth International Conference on Information and Communication Technologies and Development (pp. 14).

[3] Alemi, F., Alemagno, S. A., Goldhagen, J., Ash, L., Finkelstein, B., Lavin, A., ... \& Ghadiri, A. (1996). Computer reminders improve on-time immunization rates. Medical Care, 34(10), 45-51.

[4] Riaz, A., Husain, S., Yousafzai, M. T., Nisar, I., Shaheen, F., Mahesar, W., ... \& Ali, A. (2018). Reasons for non-vaccination and incomplete vaccinations among children in Pakistan. Vaccine, 36(35), 5288-5293.

[5] Khan, M. U., \& Ahmad, A. (2015). Polio vaccination in Pakistan. The Lancet, 386(9991), 337.

[6] Bhandari, B., Mandowara, S. L., \& Gupta, G. K. (1990). Evaluation of vaccination coverage. The Indian Journal of Pediatrics, 57(2), 197-201.

[7] Razaq, S., Batool, A., Ali, U., Khalid, M. S., Saif, U., \& Naseem, M. (2016, November). Iterative Design of an Immunization Information System in Pakistan. In Proceedings of the 7th Annual Symposium on Computing for Development (pp. 1-10).
[8] Clark, S. J., Butchart, A., Kennedy, A., \& Dombkowski, K. J. (2011). Communication modes for immunization reminder/recall: parent experiences and preferences. Pediatrics, 128(5), e1100-5.

[9] W Brown, D. (2012). COMMENTARY Child Immunization Cards: Essential Yet Underutilized in National Immunization Programmes. The Open Vaccine Journal, 5(1).

[10] Gellin, B. G., Maibach, E. W., \& Marcuse, E. K. (2000). Do parents understand immunizations? A national telephone survey. Pediatrics, 106(5), 1097-1102.

[11] Kumari, S., Haripriya, A., Aruna, A., Vidya, D. S., \& Nithy, M. N. (2017, March). Immunize-Baby steps for smart healthcare: Smart solutions to child vaccination. In 2017 International Conference on Innovations in Green Energy and Healthcare Technologies (IGEHT) (pp. 1-4). IEEE.

[12] M. U. Khan, A. Ahmad, "Polio Vaccination in Pakistan," The Lancet: Elsevier, no. 386(9991), pp. 337, $2018 . \quad$ DOI: $\quad$ https://doi.org/10.1016/S01406736(15)61405-2.

[13] Vaz, O. M., Ellingson, M. K., Weiss, P., Jenness, S. M., Bardají, A., Bednarczyk, R. A., \& Omer, S. B. (2020). Mandatory vaccination in Europe. Pediatrics, 145(2).

[14] Johnson, N. F., Velásquez, N., Restrepo, N. J., Leahy, R., Gabriel, N., El Oud, S., ... \& Lupu, Y. (2020). The online competition between pro-and anti-vaccination views. Nature, 582(7811), 230-233.

[15] Hussain, M., Majeed, S., Fatima, M., \& Shaukat, S. (2020). 2019 a challenging year for polio control in Pakistan.

[16] Sullivan, E., Masood, T., Javed, W., Bagshaw, K., Ollis, S., Regmi, P., \& Gardezi, S. M. A. (2020). Electronic immunization information systems: a case report of lessons learned from implementation in Pakistan. Mhealth, 6.

[17] Zaidi, S., Shaikh, S. A., Sayani, S., Kazi, A. M., Khoja, A., Hussain, S. S., \& Najmi, R. (2020). Operability, acceptability, and usefulness of a mobile app to track routine immunization performance in rural Pakistan: interview study among vaccinators and key informants. JMIR mHealth and uHealth, 8(2), e16081.

[18] Timothy, O. O., Shakirat, Y. R., \& Bukola, B. F. (2020). Improve Efficiency in Management andAdministration of Immunization System through a Centralized Database System. Journal of Computer Science \& Control Systems, 13(2).

[19] Aliu, O. (2020). VaxInfo: An Online Service for Managing Immunization Records and Information.

[20] Timothy, O. O., Shakirat, Y. R., \& Bukola, B. F. (2020). Improve Efficiency in Management andAdministration of Immunization System through a Centralized Database System. Journal of Computer Science \& Control Systems, 13(2). 